\title{
OTIMIZAÇÃO ESTATÍSTICA DA PRODUÇÃO DE BIODIESEL A PARTIR DE ÓLEOS RESIDUAIS DE FRITURAS EM ROTA ETÍLICA
}

\author{
Fausto de Souza Pagan'1, Mário Sérgio da Luz², Deusmaque Carneiro Ferreira ${ }^{3}$ \\ 'Mestrando em Química, pelo Programa de Pós-Graduação Multicêntrico em Química de \\ Minas Gerais junto à Universidade Federal do Triângulo Mineiro. \\ 2Professor Doutor do Departamento de Engenharia Ambiental da Universidade Federal do \\ Triângulo Mineiro. \\ ${ }^{3}$ Professor Doutor do Departamento de Engenharia Ambiental da Universidade Federal do \\ Triângulo Mineiro (Email:deusmaque@hotmail.com), Uberaba, Minas Gerais, Brasil.
}

\section{Recebido em: 03/10/2016 - Aprovado em: 21/11/2016 - Publicado em: 05/12/2016 DOI: 10.18677/EnciBio 2016B 155}

\begin{abstract}
RESUMO
O objetivo do presente estudo foi otimizar a síntese de biodiesel a partir de óleos residuais de processos de frituras. Para os experimentos, foram realizados planejamentos estatísticos, indicativos para aferição de interação das variáveis, tendo por rota de trabalho a transesterificação alcalina em rota etílica em função dos rendimentos mássicos totais de produção do biodiesel. Os planejamentos foram levados via composto central, as variáveis selecionadas foram o tempo de reação, a massa de etanol e a massa de hidróxido de sódio. O biodiesel foi caracterizado segundo os principais parâmetros estabelecidos pela Agência Nacional do Petróleo, Gás Natural e Biocombustíveis (ANP). As rotas otimizadas apresentaram rendimentos de aproximadamente $93 \%$. As análises físico-químicas das amostras de biodiesel apresentaram valores em consonância com os valores estabelecidos pela ANP. Essa forma de produção de combustível renovável não compete com os setores alimentícios, além de trazer o óleo residual de fritura ao ciclo produtivo e eliminar os severos impactos ambientais em decorrência do descarte indevido desse resíduo nos recursos hídricos.
\end{abstract}

PALAVRAS-CHAVE: biodiesel, óleo residual de fritura, otimização estatística.

\section{STATISTICAL OPTIMIZATION OF BIODIESEL PRODUCTION FROM WASTE FRYING OIL USING ETHANOL}

\begin{abstract}
In the present study, optimization of the biodiesel synthesis from waste frying oil has been done. Ethanol content, sodium hydroxide content and cooking time were selected as the experimental parameters. The optimized route leads to a biodiesel conversion of $~ 93 \%$ in which was characterized according to the stander parameters established by the Brazilian National Agency of Petroleum (ANP). All physical properties analyzed in this work are in according to established by the ANP. Releases waste cooking oils into the environment can cause environmental problems and clogs inside drainage pipes. Therefore, using waste frying oil as an alternative source of energy is one of promising ways to reduce environmental impacts and also can improve economic viability of biodiesel.
\end{abstract}

KEYWORDS: biodiesel, statistical optimization, waste frying oil. 


\section{INTRODUÇÃO}

Um dos grandes desafios da atualidade consiste em suprir a demanda energética a partir de alternativas tanto econômicas quanto sustentáveis. Nessa perspectiva, destaca-se a produção de biodiesel a partir do uso de biomassa. As vantagens da utilização do biodiesel consistem no fato de ser um combustível renovável, não tóxico e menos poluente que os derivados fósseis, como o petróleo (TOLMASQUIM et al., 2007).

O biodiesel é o produto da transformação química do óleo vegetal ou gordura animal através de uma transesterificação, que ocorre por adição de álcool (metanol ou etanol) na presença de um catalisador $(\mathrm{NaOH}$ ou $\mathrm{KOH})$. O produto da transesterificação é uma massa constituída por duas fases que podem ser separadas por decantação ou centrifugação. A fase mais densa é a glicerina bruta, contendo geralmente $50 \%$ de glicerol e várias impurezas, e a menos densa é o biodiesel, igualmente impregnado de impurezas (OLIVEIRA et al., 2013).

Assim, o uso de biocombustíveis corrobora com o desenvolvimento e a sustentabilidade do planeta. Dessa forma, a população em geral será beneficiada uma vez que essa matriz energética libera menor quantidade de poluentes na atmosfera, principalmente os óxidos de enxofre, responsáveis pela chuva ácida (SHEEHAN et al., 1998).

A produção de biodiesel, já bem consolidada no Brasil e no mundo, há mais de uma década, é um assunto que continua a atrair interesse de vários setores, especialmente da indústria de biocombustíveis e dos pesquisadores em geral, uma vez que sempre há o objetivo de aumentar a qualidade e aprimorar o processo de produção deste combustível ainda muito valorizado (CREMONEZ et al., 2015).

Aspectos ambientais, econômicos, políticos, culturais e técnicos relativos ao uso dos biocombustíveis têm sido comumente abordados, especialmente na agricultura (BUYUKKAYA, 2010). O uso de matérias-primas de baixo custo representa também uma boa alternativa para baratear o processo de obtenção de biodiesel. Ácidos graxos destilados obtidos no processo de refino de óleos vegetais são subprodutos com baixo valor comercial em comparação aos óleos refinados (REIS et al., 2015).

No contexto de matéria prima para a produção de biodiesel surge o óleo de fritura, considerado resíduo, de elevado potencial poluente (WITSCHINSKI et al., 2012). Cada litro de óleo despejado no esgoto tem capacidade para poluir cerca de um milhão de litros de água. Além disso, essa contaminação prejudica o funcionamento das estações de tratamento de água (MONTEIRO et al., 2013).

O acúmulo de óleos e gorduras nos encanamentos pode causar entupimentos, refluxo de esgoto e até rompimentos nas redes de coleta (PAITER et al., 2015). A presença de óleos nos rios cria uma barreira que dificulta a entrada de luz e a oxigenação da água, comprometendo assim, a base da cadeia alimentar aquática (MELLO et al., 2011). A produção de biodiesel a partir de óleo residual de fritura repercute na redução do impacto ambiental causado pelo descarte inadequado desse resíduo nos mananciais de água e no solo (KNOTHE et al., 2003).

A principal rota de produção do biodiesel é a transesterificação alcalina (MENDOW et al., 2011). A Figura 1 apresenta a equação química de uma reação de transesterificação entre um triglicerídeo e um álcool de cadeia curta, produzindo três moléculas de éster de ácido graxo (biodiesel) e uma molécula de glicerol (VOLLHARDT \& SCHORE, 2004). 


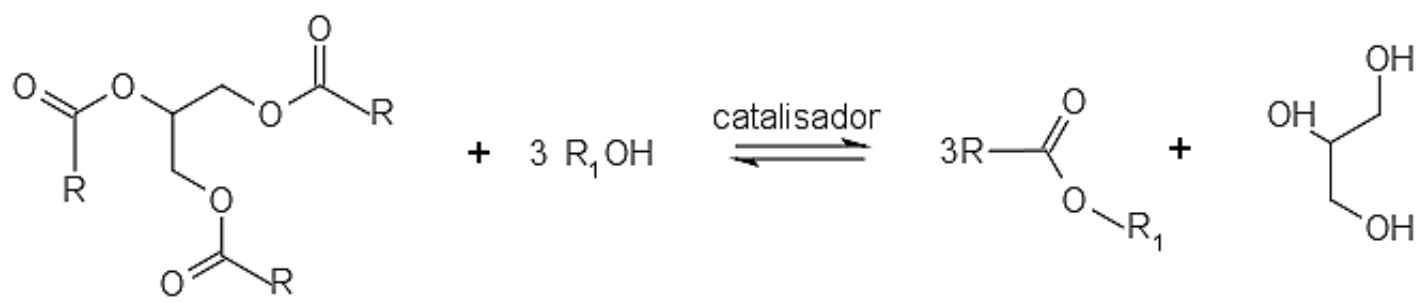

FIGURA 1- Alcoólise de óleos vegetais. "R" representa grupamentos alquila contendo em média de 18 a 22 carbonos e $R_{1}$ é o grupamento alquila utilizado como agente de transesterificação.

Fonte: Autores, 2016.

As reações com catalisadores básicos são as mais empregadas porque resultam em processos mais rápidos, com maiores rendimentos de alquil ésteres de ácidos carboxílicos de cadeia longa e requerem condições operacionais mais moderadas (SATO et al., 2016). Em relação aos alcoóis utilizados na produção do biodiesel, as indústrias de biodiesel, geralmente, empregam o metanol. Isso se deve a maior reatividade do metanol em relação ao etanol, uma vez que, independentemente do catalisador ou das condições em que se realize a transesterificação, o metanol é mais eficiente que o etanol, seja em velocidade quanto no rendimento final da reação (TALUKDER et al., 2010).

Recentes estudos mostram a crescente aplicação do etanol na produção de biodiesel. $O$ uso de etanol em vez de metanol na reação de transesterificação traz algumas vantagens tais como: Produção de biodiesel com maior estabilidade oxidativa, melhor capacidade de lubrificação e melhor ponto de fluidez (STAMENKOVIĆ et al., 2011). Vale destacar também que o etanol é menos tóxico que o metanol, além da tradição do Brasil na produção de álcool etílico e a dependência externa do álcool metílico (ARANSIOLA et al., 2014). O presente estudo objetivou otimizar a produção de biodiesel a partir de óleos residuais de frituras em rota etílica.

\section{MATERIAL E MÉTODOS}

O óleo residual de fritura foi coletado mensalmente, de fevereiro de 2015 a fevereiro de 2016, no restaurante universitário do Instituto de Ciências Tecnológicas e Exatas da Universidade Federal do Triângulo Mineiro. O óleo residual coletado foi armazenado em galões plásticos de cinco litros. No total, foram coletados 25 litros de óleo. O pré-tratamento da matéria prima foi realizado através de filtração simples da amostra de óleo. A produção do biodiesel em rota etílica ocorreu por meio da reação de transesterificação alcalina, nas condições ambientes, em balão de três bocas de $250 \mathrm{~mL}$.

A otimização estatística da reação de transesterificação para produção de biodiesel foi feita a partir do Planejamento Composto Central (PCC). As variáveis foram estudadas com cinco diferentes níveis $(-\alpha,-1,0,1,+\alpha)$, sendo que cada nível possui seu respectivo valor nominal. As variáveis selecionadas foram o tempo de reação (minutos), a massa de etanol (gramas) e a massa de hidróxido de sódio (gramas). Como são três variáveis $(n=3)$ selecionadas, o número de ensaios $\left(2^{n}\right)$ será igual a oito pontos fatoriais, contando com mais seis pontos axiais e mais três pontos centrais, totalizando 17 ensaios.

Após a definição das variáveis, foram delimitados os valores máximos (limite superior) e mínimos (limite inferior) dos parâmetros de modo que a principal região 
de rendimento fosse identificada. As variáveis em estudo e seus respectivos limites encontram-se apresentados na Tabela 1.

TABELA 1- Variáveis e limites de trabalho definidos para as rotas experimentais

\begin{tabular}{cccc}
\hline Variáveis & Lim. Inferior & Medial & Lim. Superior \\
\hline Catalisador NaOH & 0,30 & 0,50 & 0,70 \\
(g) & 15,00 & 20,00 & 25,00 \\
Etanol PA (g) & 60,00 & 70,00 & 80,00 \\
Tempo em & -1 & 0 & +1 \\
(minutos) & Codificação & & \\
\hline
\end{tabular}

Após definir as variáveis e parâmetros de trabalho, o Planejamento Composto Central (PCC) foi elaborado para cada variável em dois níveis de trabalho acrescido a dois pontos (alfa) que ortogonalizam o planejamento, pontos extremos da variação. O PCC estuda os efeitos da interação dos parâmetros em questão. Cada variável então é estudada nos três níveis já definidos anteriormente $(-1,0,+1)$ e em outros dois níveis que serão classificados como $-\alpha$, $+\alpha$, estes parâmetros foram utilizados para se obter um planejamento, onde a matriz de variância e covariância é diagonal e os parâmetros estimados não são correlacionados entre si (BOX et al., 1978). Os valores de a foram calculados pela Equação 1:

$$
\begin{aligned}
& \alpha=\left(\frac{Q, G}{4}\right)^{0.25} \\
& \text { onde } Q=\left[(G+T)^{0,5}-G^{0,5}\right]^{2} \text {, sendo } \\
& \mathrm{G}=\text { número de pontos fatoriais }\left(\mathrm{G}=2^{\mathrm{k}}\right. \text {, se completo); } \\
& \mathrm{T}=2^{\mathrm{k}}+\text { número de réplicas no ponto central + número de pontos adicionais. } \\
& \text { A matriz de planejamento é apresentada na Tabela } 2 .
\end{aligned}
$$

TABELA 2- Matriz de planejamento

\begin{tabular}{cccc}
\hline Experimentos & $\begin{array}{c}\text { Massa de NaOH } \\
\text { em gramas } \\
\text { (codificada) }\end{array}$ & $\begin{array}{c}\text { Massa de etanol } \\
\text { PA em gramas } \\
\text { (codificada) }\end{array}$ & $\begin{array}{c}\text { Tempo em } \\
\text { minutos } \\
\text { (codificada) }\end{array}$ \\
\hline $\mathbf{1}$ & $0,30(-1)$ & $15,00(-1)$ & $60,00(-1)$ \\
$\mathbf{2}$ & $0,70(1)$ & $15,00(-1)$ & $60,00(-1)$ \\
$\mathbf{3}$ & $0,30(-1)$ & $25,00(1)$ & $60,00(-1)$ \\
$\mathbf{4}$ & $0,70(1)$ & $25,00(1)$ & $60,00(-1)$ \\
$\mathbf{5}$ & $0,30(-1)$ & $15,00(-1)$ & $80,00(1)$ \\
$\mathbf{6}$ & $0,70(1)$ & $15,00(-1)$ & $80,00(1)$ \\
$\mathbf{7}$ & $0,30(-1)$ & $25,00(1)$ & $80,00(1)$ \\
$\mathbf{8}$ & $0,70(1)$ & $25,00(1)$ & $80,00(1)$ \\
$\mathbf{9}$ & $0,50(0)$ & $20,00(0)$ & $57,12(-\alpha)$ \\
$\mathbf{1 0}$ & $0,50(0)$ & $20,00(0)$ & $82,87(\alpha)$ \\
$\mathbf{1 1}$ & $0,50(0)$ & $13,56(-\alpha)$ & $70,00(0)$ \\
$\mathbf{1 2}$ & $0,50(0)$ & $26,43(\alpha)$ & $70,00(0)$ \\
$\mathbf{1 3}$ & $0,24(-\alpha)$ & $20,00(0)$ & $70,00(0)$ \\
$\mathbf{1 4}$ & $0,76(\alpha)$ & $20,00(0)$ & $70,00(0)$ \\
$\mathbf{1 5}$ & $0,50(0)$ & $20,00(0)$ & $70,00(0)$ \\
$\mathbf{1 6}$ & $0,50(0)$ & $20,00(0)$ & $70,00(0)$ \\
$\mathbf{1 7}$ & $0,50(0)$ & $20,00(0)$ & $70,00(0)$ \\
\hline
\end{tabular}

No preparo da matéria prima realizou-se filtragem simples do óleo residual, visando à retirada de sólidos suspensos que derivam do processo de fritura dos ENCICLOPÉDIA BIOSFERA, Centro Científico Conhecer - Goiânia, v.13 n.24; p. 16952016 
alimentos. Em seguida, preparou-se o catalisador dissolvendo, em béquer de 250 $\mathrm{mL}$, a massa do catalisador $(\mathrm{NaOH})$ na respectiva massa de etanol PA conforme as quantidades especificadas na Tabela 2. Na sequência, uma alíquota de 50,00 g de óleo residual de fritura foi adicionada ao béquer contendo o catalisador para cada experimento, prosseguindo em agitação branda pelo tempo previamente determinado no planejamento experimental, nas condições ambientes.

$\mathrm{Na}$ sequência, a mistura foi transferida quantitativamente para um funil de separação de $200 \mathrm{~mL}$, após repouso de 24 horas para a completa separação de fases, sendo a mais clara na porção superior (biodiesel) e a mais escura na porção inferior (glicerol). Na sequência, a porção inferior foi retirada do balão e a fase sobrenadante, de coloração mais clara, foi então lavada com $20 \mathrm{~mL}$ de água destilada a temperatura ambiente. Esse procedimento foi realizado quatro vezes para a máxima remoção do excesso de catalisador e demais substâncias hidrossolúveis contidas na amostra. O material obtido foi então submetido as seguintes análises de caracterização físico-química: massa específica, ponto de entupimento, índice de acidez e viscosidade cinemática.

A massa específica foi determinada pela técnica da picnometria. O ponto de congelamento foi determinado via utilização de termopar (NBR 14747) sendo então registrada a temperatura em que apareceram os primeiros cristais. Os índices de acidez e viscosidade cinemática foram realizados de acordo com as normas técnicas especificadas pela ANP, respectivamente NBR 14448 e AST D 445 (ANP, 2003).

O tratamento estatístico dos resultados obtidos para essas caracterizações foi feito através do cálculo da média e do desvio padrão para cada análise realizada em triplicata.

\section{RESULTADOS E DISCUSSÃO}

A Tabela 3 apresenta as massas de biodieseis produzidas e as taxas de conversão (rendimento percentual) para a reação de transesterificação alcalina em rota etílica para os 17 experimentos.

TABELA 3- Valores de rendimento mássico para o biodiesel obtido nas diferentes rotas experimentais.

\begin{tabular}{|c|c|c|c|c|c|c|}
\hline & $\begin{array}{l}\text { Hidróxido } \\
\text { de sódio } \\
\text { (g) }\end{array}$ & $\begin{array}{c}\text { Etanol PA } \\
\text { (g) }\end{array}$ & $\begin{array}{c}\text { Tempo } \\
\text { (min) }\end{array}$ & $\begin{array}{c}\text { Óleo } \\
\text { residual } \\
(\mathrm{g})\end{array}$ & $\begin{array}{l}\text { Biodiesel } \\
\text { (g) }\end{array}$ & $\begin{array}{c}\text { Rendimento } \\
\mathrm{m} / \mathrm{m}(\%)\end{array}$ \\
\hline 1 & 0,30 & 15,00 & 60,00 & 50,12 & 31,28 & 62,41 \\
\hline 2 & 0,70 & 15,00 & 60,00 & 50,10 & 28,12 & 56,12 \\
\hline 3 & 0,30 & 25,00 & 60,00 & 50,14 & 38,82 & 77,42 \\
\hline 4 & 0,70 & 25,00 & 60,00 & 50,00 & 42,26 & 84,52 \\
\hline 5 & 0,30 & 15,00 & 80,00 & 50,04 & 41,46 & 82,85 \\
\hline 6 & 0,70 & 15,00 & 80,00 & 50,13 & 43,95 & 87,67 \\
\hline 7 & 0,30 & 25,00 & 80,00 & 50,07 & 42,70 & 85,28 \\
\hline 8 & 0,70 & 25,00 & 80,00 & 50,08 & 41,64 & 83,14 \\
\hline 9 & 0,50 & 20,00 & 57,00 & 50,11 & 47,04 & 93,87 \\
\hline 10 & 0,50 & 20,00 & 83,00 & 50,00 & 33,74 & 67,48 \\
\hline 11 & 0,50 & 13,56 & 70,00 & 50,00 & 42,34 & 84,68 \\
\hline 12 & 0,50 & 26,44 & 70,00 & 50,00 & 32,94 & 65,88 \\
\hline 13 & 0,24 & 20,00 & 70,00 & 50,10 & 31,50 & 62,87 \\
\hline 14 & 0,76 & 20,00 & 70,00 & 50,12 & 43,04 & 85,87 \\
\hline 15 & 0,50 & 20,00 & 70,00 & 50,02 & 42,22 & 84,40 \\
\hline 16 & 0,50 & 20,00 & 70,00 & 50,00 & 42,85 & 85,70 \\
\hline 17 & 0,50 & 20,00 & 70,00 & 50,06 & 42,90 & 85,69 \\
\hline
\end{tabular}

ENCICLOPÉDIA BIOSFERA, Centro Científico Conhecer - Goiânia, v.13 n.24; p. 1696 
A partir dos valores de rendimento obtidos para cada experimento, empregando o software Statistica ${ }^{\circledR}$, foi possível realizar a análise do PCC através das superfícies de respostas e do gráfico de Pareto. As superfícies forneceram valores da variável de retorno, rendimento percentual de biodiesel em cada rota sintética, em relação a outras duas variáveis de controle escolhidas para estudo, fornecendo assim, as regiões de maiores (máximo) e menores (mínimos) resultados para o rendimento.

A Figura 2 mostra a superfície de resposta que confrontam as variáveis: massa do catalisador, tempo de reação e massa de etanol PA em função do rendimento mássico para a rota de transesterificação alcalina.

a)

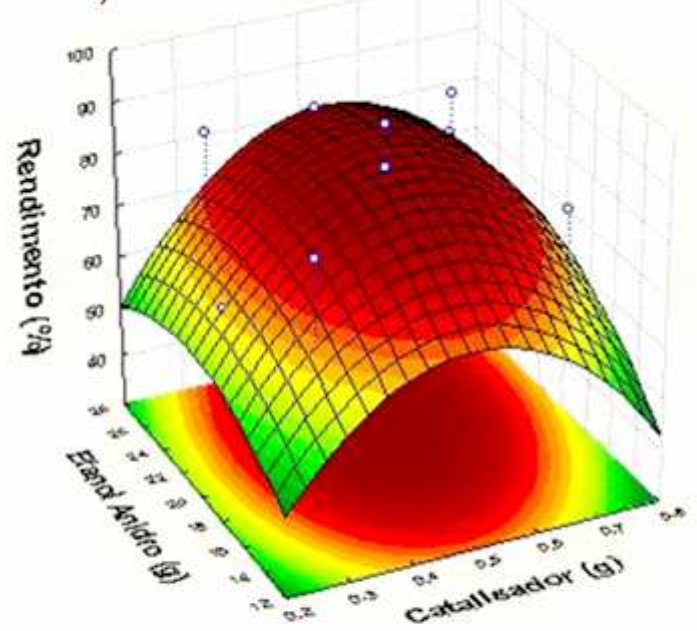

b)

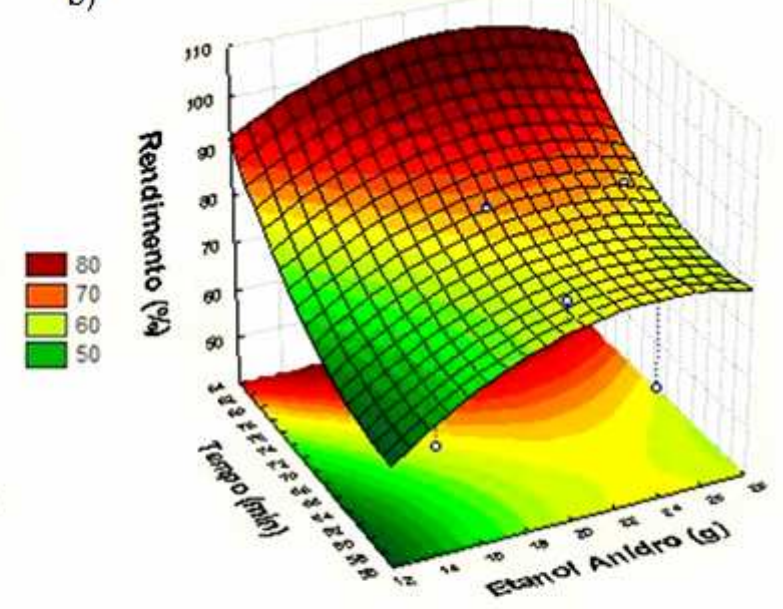

c)

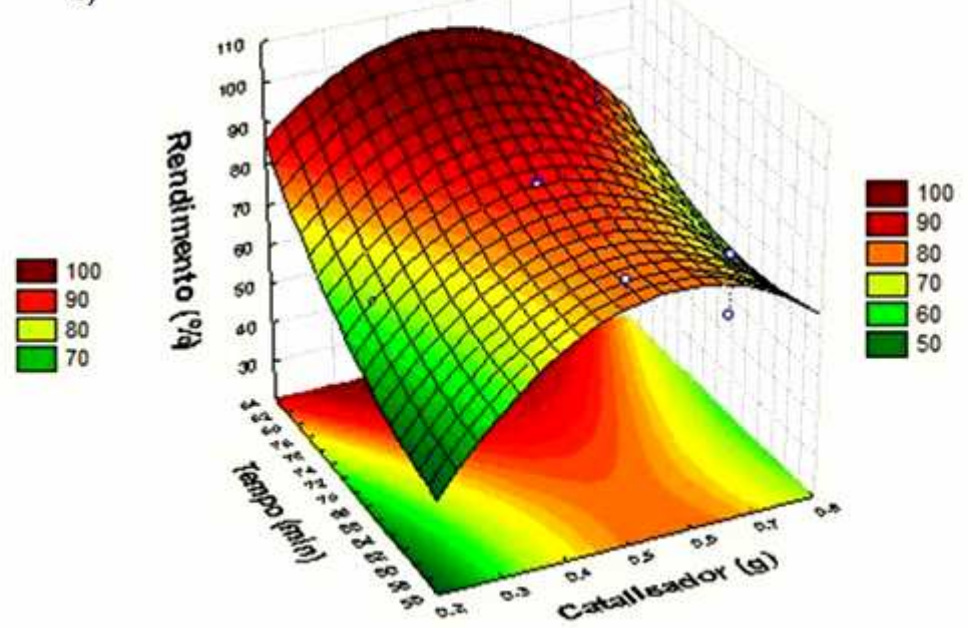

FIGURA 2- Superfícies de respostas para os valores dos rendimentos mássicos de biodiesel em função: (a) etanol anidro e catalisador, (b) etanol anidro e tempo, (c) catalisador e tempo.

Fonte: Autores, (2016).

Através dos coeficientes do modelo proposto pelo Statistica $\circledast$, a equação matemática gerada ajustou bem aos valores observados experimentalmente, uma vez que a regressão linear (valores preditos e observados) apresentou coeficiente de correlação linear igual a 0,98. MELO et al., (2011) também encontraram valor 
semelhante para o coeficiente de correlação linear $(0,97)$ em estudo de otimização das variáveis envolvidas na reação de transesterificação alcalina em rota etílica do sebo bovino.

O eixo do catalisador (Figura 2a), referente à superfície de resposta apresenta comportamento em arco dentro dos limites propostos para os experimentos (Tabela 2), uma vez que, em baixas quantidades de catalisador a formação in situ do íon alcóxido $\left(\mathrm{CH}_{3} \mathrm{CH}_{2} \mathrm{O}^{-}\right)$ficou comprometida no intervalo de tempo considerado, enquanto que o excesso de catalisador deixa o meio alcalino favorecendo a reação de saponificação. $O$ eixo do etanol anidro também se apresenta em forma de arco, onde os valores mais baixos de álcool refletem a menor efetividade de formação do íon alcóxido a partir do etanol PA, enquanto que para valores maiores de etanol, o rendimento fica ligado a baixos valores pela interferência do excesso de catalisador no meio.

$\mathrm{Na}$ superfície de resposta (Figura 2b), percebe-se que o aumento do rendimento é diretamente proporcional ao aumento da quantidade de álcool, deslocamento do equilíbrio químico da reação de transesterificação, facilitando também a formação do íon alcóxido. Observa-se também que maiores rendimentos também são observados para maiores tempos, diferente do efeito negativo encontrado para altos valores de catalisadores, favorecendo assim a reação de saponificação. Relação semelhante também foi encontrada em estudo paramétrico da produção de biodiesel em rota etílica a partir de sebo bovino (MELO et al., 2011).

A superfície de resposta (Figura 2c), mostra que maiores valores de tempo influem positivamente no rendimento, dando o formato característico dessa superfície, que apresenta região de maximização do rendimento em valores medianos de catalisador e valores altos de tempo. Os efeitos das variáveis estudadas estão apresentados no Gráfico de Pareto (FIGURA 3), em que as variáveis que influem com maior efetividade encontram-se em barras mais extensas.

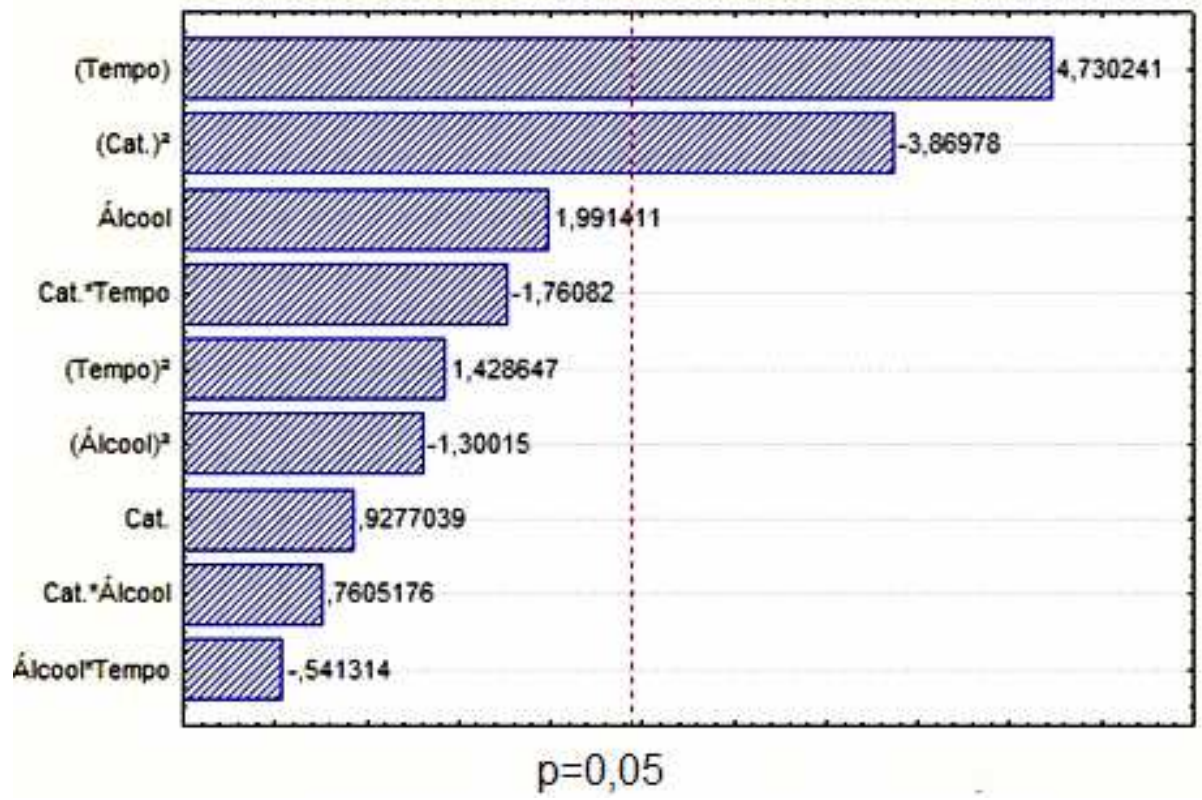

FIGURA 3- Gráfico de Pareto para a reação de transesterificação alcalina em rota etílica com intervalo de confiança de 95\%. Fonte: Autores, (2016). 
Na Figura 3 observa-se que a variável tempo apresenta maior efeito positivo no rendimento do biodiesel, enquanto que a variável catalisador influiu negativamente, em proporção quadrática, no rendimento. Os valores que maximizaram o rendimento de biodiesel empregando etanol PA, a partir de $50 \mathrm{~g}$ de óleo residual de fritura, foram: 0,56 $\mathrm{g}$ de hidróxido de sódio, 24,50 g de etanol PA e tempo de reação igual a 60 minutos, nas condições ambientes, sob agitação constante. DIB (2010) também encontrou proporções estequiométricas similares para produção de biodiesel em rota etílica, empregando hidróxido de sódio como catalisador, a partir de óleo residual de fritura reciclado em um moto-gerador.

Análises em triplicata foram realizadas no ponto de máximo, para a verificação dos valores de rendimentos e caracterização físico-química do produto obtido. A Tabela 4 apresenta os valores das análises físico-químicas do biodiesel no ponto de ótimo. Também foram apresentados, para fim de comparação, os referidos valores estabelecidos pela RESOLUÇÃO № 45 da ANP de 25 de agosto de 2014 para o biodiesel sem mistura com diesel (B100).

TABELA 4- Resultados das análises físico-químicas para as amostras de biodiesel produzidas no ponto de máximo rendimento

\begin{tabular}{|c|c|c|c|c|}
\hline $\begin{array}{l}\text { Amostras do } \\
\text { biodiesel da } \\
\text { reação } \\
\text { maximizada }\end{array}$ & $\begin{array}{l}\text { Densidade } \\
\text { do } \\
\text { biodiesel } \\
\left(\mathrm{g} \mathrm{cm}^{-3} \mathrm{a}\right. \\
\left.2^{\circ} \mathrm{C}\right)\end{array}$ & $\begin{array}{l}\text { Ponto de } \\
\text { entupimento } \\
\left({ }^{(C)}\right)\end{array}$ & $\begin{array}{l}\text { Índice de } \\
\text { acidez } \\
(\mathrm{mg} \text { de } \\
\mathrm{KOH} / \mathrm{g})\end{array}$ & $\begin{array}{l}\text { Viscosidade } \\
\text { cinemática } \\
\left(\mathrm{mm}^{2} / \mathrm{s} \text { a } 40 \mathrm{C}\right)\end{array}$ \\
\hline Amostra 1 & $0,87 \pm 0,01$ & $4,00 \pm 0,20$ & $0,10 \pm 0,02$ & $5,32 \pm 0,22$ \\
\hline Amostra 2 & $0,87 \pm 0,01$ & $5,00 \pm 0,30$ & $0,11 \pm 0,04$ & $5,64 \pm 0,37$ \\
\hline Amostra 3 & $0,87 \pm 0,01$ & $5,00 \pm 0,26$ & $0,10 \pm 0,06$ & $5,40 \pm 0,52$ \\
\hline $\begin{array}{l}\text { Valores } \\
\text { estabelecidos } \\
\text { pela ANP }\end{array}$ & 0,85 e 0,90 & $\begin{array}{c}\text { Até } 10 \text { (varia } \\
\text { de acordo com } \\
\text { a região) }\end{array}$ & Até 0,50 & 3 a 6 \\
\hline
\end{tabular}

A rota otimizada apresentou taxa de conversão da ordem de $93 \%$. Os valores encontrados para a viscosidade cinemática ficaram próximos do limite estabelecido pela ANP. SANTOS et al. (2014) também encontraram valores de viscosidade cinemática para biodiesel sintetizado a partir de óleo residual de fritura próximos do limite superior estabelecido pela ANP. Como o biodiesel não é utilizado na sua forma pura (B100), a mistura com diesel poderá reduzir os valores da viscosidade cinemática do biodiesel de óleo residual de fritura para valores similares ao ciclo diesel (SILVA, 2013).

Após análise conjunta das caracterizações físico-químicas (Tabela 4) verificouse que os resultados obtidos foram condizentes com os limites estabelecidos pela ANP. Com isso, o produto obtido no ponto de ótimo pode ser classificado na categoria de biodiesel segundo as análises de densidade, ponto de entupimento, índice de acidez e viscosidade cinemática.

\section{CONCLUSÃO}

O resultado da produção maximizada de biodiesel a partir de óleo residual de fritura, com o auxílio da técnica de superfícies de resposta, se mostrou satisfatória, a caracterização do produto obtido apresentou consonância com os principais parâmetros estabelecidos pela ANP. 
Os rendimentos obtidos para a reação otimizada de transesterificação alcalina em rota etílica foram superiores a $90 \%$. Sendo estes, considerados ótimos resultados quando se trata de uma matéria prima tão complexa e diversificada quanto o óleo residual de fritura.

Portanto, a produção de biodiesel a partir de óleo residual de fritura e etanol PA em catálise alcalina constitui-se de uma alternativa viável de aplicação da reciclagem do óleo, podendo gerar renda, trazer o resíduo de volta ao ciclo de consumo e eliminar os severos impactos ambientais em decorrência do descarte indevido desse resíduo nos recursos hídricos.

\section{REFERÊNCIAS}

ANP - AGÊNCIA NACIONAL DE PETRÓLEO, GÁS NATURAL E BIOCOMBUSTÍVEIS. Portaria ANP $n^{\circ}$ 255, de 15 de setembro de 2003. Estabelece a especificação do biodiesel puro a ser adicionado ao óleo diesel automotivo para testes em frotas cativas ou para uso em processo industrial específico nos termos da Portaria ANP $\mathrm{n}^{\circ}$ 240, de 25 de agosto de 2003. Brasília: ANP, 2003. Disponível em: < https://www.legisweb.com.br/legislacao/?id=185852>. Acesso em: 15 set. 2016.

ARANSIOLA, E. F.; OJUMU, T.V.; OYEKOLA, O.O.; MADZIMBAMUTO, T.F.; IKHUOMOREGBE, D.I.O. A review of current technology for biodiesel production: State of the art. Biomass and Bioenergy, v.61, 276-297, 2014. doi: 10.1016/j.biombioe.2013.11.014

BOX, G.E.P.; HUNTER. W.G.; HUNTER. J.S. Statistics for Experimenters: An Introduction to Design, Data Analysis and Model Building. John Wiley and Sons Inc., New York, USA. ISBN-13: 9780471093152 , Page- 653, 1978.

BUYUKKAYA, E. Effects of biodiesel on a DI diesel engine performance, emission and combustion characteristics. Fuel, v.89, p.3099-3105, 2010. doi: 10.1016/j.biombioe. 2011.02.055.

CREMONEZ, A. P.; FEROLDI, M.; NADALETI, W.C; ROSSI, E.; FEIDEN, A.; CAMARGO, M.P.; CREMONEZ, F.E.; KLAJN, F.F. Biodiesel production in Brazil: Current scenario and perspectives. Renewable sustainable energy Rev., v.42, p.415-428, 2015. http://dx.doi.org/10.1016/j.rser.2014.10.004

DIB, F. H. Produção de biodiesel a partir de óleo residual reciclado e realização de testes comparativos com outros tipos de biodiesel e proporções de mistura em um moto-gerador. 2010. 118 f. Dissertação (Mestrado em Engenharia Mecânica) - Faculdade de Engenharia de llha Solteira, Universidade Estadual Paulista Júlio De Mesquita Filho, Ilha Solteira, 2010.

KNOTHE, G.; DUNN, R. O.; BAGBY, M.O. Biodiesel: the use of vegetable oils and their derivatives as alternative diesel fuels. ACS Symposium Series, v.42, p.172208, 2003. doi: 10.1021/bk-1997-0666.ch010

MELO, A. M.; SILVA, F. L. H.; GOMES, J. P.; ALVES, N. M. C. Aproveitamento de Resíduos de Restaurante na Obtenção de Adubo Orgânico para Produção de Alface 
e Mudas de Maracujazeiro e Mamoeiro. Revista Brasileira de Produtos Agroindustriais, v.13, n. especial, p. 325-335, 2011. Disponível em: http://www.deag.ufcg.edu.br/rbpa/rev13e/Art13E1.pdf. Acesso em: 12 nov. 2016.

MELO, T. C.; BEGNINI, M. L.; FERREIRA, D. C. Estudo paramétrico das variáveis envolvidas na reação de transesterificação etílica do sebo bovino. Enciclopédia Biosfera, v.7, n.13, p. 1821-1832, 2011

MENDOW, G.; VEIZAGA, N.S.; SÁNCHEZ, B.S.; QUERINI, C.A. Biodiesel production by two-stage transesterification with ethanol. Bioresour. Technol., v.102, n.22, p.10407-10413, 2011. doi: 10.1016/j.biortech.2011.08.052.

MONTEIRO, L. A.; PIANOVSKI JÚNIOR, G.; VELÁSQUEZ; J.A.; ROCHA, D.R.; BUENO, A.B. Performance impact of the application of castor oil biodiesel in diesel engines. Eng. Agríc., v. 33, n. 6, p. 1165-1171, 2013. Disponível em: $<$ http://www.scielo.br/scielo.php?script=sci_arttext\&pid=S0100-

69162013000600009\&Ing=en\&nrm=iso>. $\quad$ Acesso em: 15 set. 2016. doi:10.1590/S0100-69162013000600009.

OLIVEIRA, J. S.; ANTONIASSI, R.; FREITAS, S.C.; MÜLLER, M.D. Composição química da glicerina produzida por usinas de biodiesel no Brasil e potencial de uso na alimentação animal. Cienc. Rural, v. 43, n. 3, p.509-512, 2013. Disponível em: $<$ http://www.scielo.br/scielo.php?script=sci_arttext\&pid=S0103-

$84782013000300022 \& \mathrm{Ing}=\mathrm{en} \& \mathrm{nrm}=\mathrm{iso}>$. Acesso em: 16 set. 2016. doi: 10.1590/S0103-84782013000300022.

PAITER, L.; GALVÃO, J. R.; STEVAN JUNIOR, S. L. Estudo empírico da degradação de óleo de soja correlacionado com a sua constante dielétrica utilizando um sensor capacitivo. Matéria, v. 20, n. 2, p. 392-398, 2015. Disponível em: $<$ http://www.scielo.br/scielo.php?script=sci_arttext\&pid=S1517-

70762015000200392\&Ing=en\&nrm=iso>. Acesso em: 16 set. 2016. doi: 10.1590/S1517-707620150002.0040.

REIS, M. C.; FREITAS, F.A.; LACHTER, E.R.; GIL, R.A.S.S.; NASCIMENTO, R.S.V.; POUBEL, R.L.; BORRÉ, L.B. Produção de biodiesel a partir de ácidos graxos provenientes do refino de óleos vegetais via catálise ácida heterogênea e microondas. Quím. Nova, v.38, n.10, p.1307-1312, $2015 . \quad$ Disponível em: $<$ http://www.scielo.br/scielo.php?script=sci_arttext\&pid=S0100-

40422015001001307\&lng=en\&nrm=iso>. Acesso em: 16 set. 2016 . doi: 10.5935/0100-4042.20150163.

RESOLUÇÃO ANP № 45 DE 25/08/2014. Disponível em: https://www.legisweb.com.br/legislacao/?id=274064. Acesso em: 12 nov. 2016

SANTOS, A. L.; KUNRATH, N. F.; SOUZA, I. S.; PANTOJA, N. V.; KISPERGHER, E. M. Obtenção e utilização de biodiesel produzido a partir de óleos residuais de fritura. In: CONGRESSO INTERNACIONAL DE BIOENERGIA, 9, 2014, São Paulo. Anais... São Paulo: Congresso Internacional de Bioenergia, 2014. 1 CD-ROM. 
SATO, R. T.; STROPPA, P.H.F.; SILVA, A.D.; OLIVEIRA, M.A.L. Fast gc-fid method for monitoring acidic and basic catalytic transesterification reactions in vegetable oils to methyl ester biodiesel preparation. Química Nova, v. 39, n. 3, p. 352-355, 2016 . .

Disponível em: <http://www.scielo.br/scielo.php?script=sci_arttext\&pid=S010040422016000300352\&lng=en\&nrm=iso>. Acesso em: 15 set. 2016. doi: $10.5935 / 0100-4042.20160027$.

SHEEHAN, J.; DUNAHAY, T.; BENEMANN, J.; ROESSLER, R. A Look Back at the U. S. Department of Energy's Aquatic Species Program. Biodiesel from Algae. Colorado: U.S. Department of Energy's

Office of Fuels Developmen, 1998. 294 p. Disponível em:< http://www.nrel.gov/docs/legosti/fy98/24190.pdf>. Acesso em: 15 set. 2016.

SILVA, T. A. R.; NETO, W. B. Estudo da Redução da Acidez do Óleo Residual para a Produção de Biodiesel Utilizando Planejamento Fatorial Fracionado. Revista Virtual de Química, v. 5, n. 5, p. 828-839, 2013. Disponível em: <http://www.uff.br/RVQ/index.php/rvq/article/download/334/333>. Acesso em: 12 out. 2016. doi: 10.5935/1984-6835.20130060

STAMENKOVIĆ, O. S.; VELIČKOVIĆ, A. V.; VELJKOVIĆ, V. B. The production of biodiesel from vegetable oils by ethanolysis: Current state and perspectives. Fuel, v.90, n.11, p.3141-3155, 2011. doi:10.1016/j.fuel.2011.06.049

TALUKDER, M.M.R.; WU, J.C.; CHUA, L.P.L. Conversion of waste cooking oil to biodiesel via enzymatic hydrolysis followed by chemical esterification. Energy \& Fuels, v. 24, p 2016-2019, 2010. doi: 10.1021/ef9011824

TOLMASQUIM, M. T.; GUERREIRO, A.; GORINI, R. Matriz energética brasileira: uma prospectiva. Novos estud. - CEBRAP, n.79, p.47-69, 2007. Disponível em: <http://www.scielo.br/pdf/nec/n79/03.pdf>. Acesso em: 15 set. 2016. doi: http://dx.doi.org/10.1590/S0101-33002007000300003

VOLLHARDT, K. P. C.; SCHORE, N. E. Química Orgânica: Estrutura e Função. Bookman: Porto Alegre, 2004.

WITSCHINSKI, F., GHISLENI, C.P., VALDUGA, E. Alterações do óleo de soja em fritura descontínua de produtos empanados congelados em uma unidade de alimentação e nutrição. Alimentos e Nutrição, v. 23, n.3, p.499-505, 2012. Disponível em: <http://servbib.fcfar.unesp.br/seer/index.php/alimentos/article/viewFile/499/1636>. Acesso em: 16 set. 2016. 